M. E. Caughey - M. J. Barcelona $\cdot$ R. M. Powell

R. A. Cahill - C. Gron - D. Lawrenz - P. L. Meschi

\title{
Interlaboratory study of a method for determining nonvolatile organic carbon in aquifer materials
}

Received: 21 October 1994 / Accepted: 7 March 1995

\begin{abstract}
The organic carbon fraction in aquifer materials exerts a major influence on the subsurface mobilities of organic and organic-associated contaminants. The spatial distribution of total organic carbon (TOC) in aquifer materials must be determined before the transport of hydrophobic organic pollutants in aquifers can be modeled accurately. Previous interlaboratory studies showed that it is difficult to measure TOC concentrations $<0.1 \%$ in aquifer materials, when total inorganic carbon (TIC) concentrations are $>1 \%$. We have tested a new analytical method designed to improve the accuracy and precision of nonvolatile TOC quantitation in geologic materials that also contain carbonate minerals. Four authentic aquifer materials and one NIST standard reference material were selected as test materials for a blind collaborative study. Nonvolatile TOC in these materials ranged from 0.05 to $1.4 \%$, while TIC ranged from 0.46 to $12.6 \%$. Sample replicates were digested with sulfurous acid, dried at $40^{\circ} \mathrm{C}$, and then combusted at $950^{\circ} \mathrm{C}$ using LECO or UIC instruments. For the three test materials that contained $>2 \%$ TIC, incomplete acidification resulted in a systematic
\end{abstract}

M. E. Caughey ( $\Delta)$

Illinois State Water Survey, 2204 Griffith Dr., Champaign, Illinois 61820 , USA

M. J. Barcelona

University of Michigan, 181 EWRE Bldg., Ann Arbor, Michigan 48109, USA

R. M. Powell

ManTech Environmental Research Services Corp., Box 1198, Ada, Oklahoma 74820, USA

R. A. Cahill

Illinois State Geological Survey, 615 E. Peabody Av., Champaign, Illinois 61820, USA

C. Grøn

Risø National Laboratory, Box 49, DK-4000, Risø, Denmark

D. Lawrenz

LECO Corp., 3000 Lakeview Av., St. Joseph, Michigan 49085, USA

P. L. Meschi

UIC, Inc., Box 863, Joliet, Illinois 60343, USA positive bias of TOC values reported by five of the six laboratories that used the test method. Participants did not have enough time to become proficient with the new method before they analyzed the test materials. A seventh laboratory successfully used an alternative method that analyzed separate liquid and solid fractions of the acidified sample residues.

Key words Aquifer material - Organic carbon Interlaboratory method evaluation

\section{Introduction}

The subsurface reactivity and transport of organic contaminants, as well as of inorganic contaminants that form complexes with dissolved organic matter, can be strongly influenced by the immobile organic carbon fraction of aquifer materials. Adsorbed organic matter influences the reactivity of metal oxides in aquifer materials $(\mathrm{Gu}$ and others 1994) and renders hydrophilic surfaces hydrophobic. Consequently, those aquifer materials become more sorptive toward organic compounds (McCarthy and $\mathrm{Za}-$ chara 1989). The bulk of the reductive capacity of aquifer materials has been shown to reside in the organic carbon fraction, in many cases far outweighing the influence of reduced iron, manganese, or sulfur mineral species (Barcelona and Holm 1991). Organic contaminant mobility studies often have involved TOC values in the $0.5-8 \%$ (weight) range (Mingelgrin and Gerstl 1983). However, Lion and others (1990) concluded that even at levels $<0.1 \%$, TOC can dominate the partitioning of hydrophobic contaminants in aquifers. Stauffer and others (1989) also stressed the importance of sorption of hydrophobic species by aquifer materials with TOC in the critical range below $0.1 \%$. Unfortunately, it is difficult to measure organic carbon accurately at these low levels and especially so in the presence of carbonate minerals.

Powell and others (1989) conducted an interlaboratory 
comparison of six instrumental methods for determining TOC in aquifer materials. They reported poor accuracy and precision when analyzing samples that had TOC concentrations $<0.1 \%$ together with TIC concentrations $>1 \%$. They identified two fundamental problems: incomplete carbonate removal prior to combusting the residue for TOC determination and incomplete reaction when using "wet" peroxydisulfate oxidation with solid samples. Using authentic soils and synthetic test samples spiked with organic carbon, Ball and others (1990) further demonstrated the inadequacies of peroxydisulfate-based methods for TOC determination in aquifer solids. Hightemperature $\left(950-1100^{\circ} \mathrm{C}\right)$ combustion in the presence of excess oxidant $\left(\mathrm{O}_{2}\right.$ or $\left.\mathrm{CuO}\right)$ is required for quantitative conversion of all sample carbon to carbon dioxide (Gibbs 1977). Methods that attempt to distinguish between organic and inorganic carbon by successive heating at two temperatures (Chichester and Chaison 1992) are matrixdependent. Krom and Berner (1983) noted that magnesiumrich calcite begins to decompose at $450^{\circ} \mathrm{C}$, but quantitative conversion of organic carbon to $\mathrm{CO}_{2}$ is not complete until $550^{\circ} \mathrm{C}$ or higher, resulting in ambiguous TIC and TOC determinations. Jackson and Roof (1992) analyzed replicate samples of 30 geologic materials for total carbon (TC) using both a LECO and a UIC carbon analyzer and achieved generally comparable values. They noted that the LECO instrument can accept a larger quantity of sample to minimize homogeneity concerns but that the nonlinear infrared detector requires empirical calibration. The UIC instrument has one half to one tenth as much sample capacity, but the stoichiometric nature of its coulometric detector eliminates the need for calibration and offers better precision.

Sample grinding prior to TOC and TIC determinations is a crucial step. It not only homogenizes the sample, but also significantly decreases the time required for acid to remove carbonates. Jones and Kaiteris (1983) recommended grinding samples $<0.063 \mathrm{~mm}$ in order to ensure complete and rapid reaction of carbonates with $85 \%$ $\mathrm{H}_{3} \mathrm{PO}_{4}$. Carbonate mineralogy affects the time required for complete reaction with acid, so slower-reacting minerals must be especially well pulverized. Al-Aasm and others (1990) found that siderite ground to $<0.074 \mathrm{~mm}$ took as long as 14 days to react completely with $100 \%$ $\mathrm{H}_{3} \mathrm{PO}_{4}$ at $50^{\circ} \mathrm{C}$; under the same conditions dolomite removal required $24 \mathrm{~h}$, while calcite reacted within about $4 \mathrm{~h}$. Videtich (1981) ground dolomite to $<0.003 \mathrm{~mm}$ in order to achieve a complete reaction with $100 \% \mathrm{H}_{3} \mathrm{PO}_{4}$ at $50^{\circ} \mathrm{C}$ within $25 \mathrm{~min}$. However, it is very difficult to grind aquifer materials to such small sizes without introducing qualitative and quantitative errors. Carbon contamination from grinder parts and losses of organic carbon from the sample during grinding and transfer can both be problematic when TOC levels are $<1 \%$.

Complete removal of all inorganic carbon from samples prior to low-level TOC determination is truly critical. Krom and Berner (1983) observed that for samples in which TIC is more than 20 times TOC, carbonate removal by acidification is required, rather than calculation of
TOC as TC minus TIC. Froelich (1980) reported that $5-$ $45 \%$ of the TOC in marine sediments is released into the liquid phase during carbonate acidification. The so-called "acid-soluble" organic carbon (ASOC) fraction must be assumed to contain suspended organic matter as well as truly soluble species. Consequently, to avoid the errors that can result from splitting an inhomogeneous liquid suspension, the entire ASOC fraction from each replicate should be analyzed for TOC. Strictly speaking, the carbon fraction remaining after complete acidification is "noncarbonate carbon," since it may contain elemental carbon and carbides in addition to true organic species.

The choice of acid to be used for carbonate removal is not simple. Although $\mathrm{H}_{3} \mathrm{PO}_{4}$ is frequently used for the acidification of geologic carbonates, combustion of residual phosphate salts shortens the useful lifetime of quartz furnace tubes. Although dilute aqueous perchloric acid $\left(2 \mathrm{M} \mathrm{HClO}_{4}\right)$ can be used to convert carbonates quantitatively to $\mathrm{CO}_{2}$, it may react with other sample components to yield perchlorates that are hazardous when heated (Schilt 1979). Furthermore, because diluted $\mathrm{HClO}_{4}$ becomes increasingly concentrated during sample residue drying, it may oxidize some labile organic compounds. Gibbs (1977) recommended using 6\% (wt) sulfurous acid $\left(\mathrm{H}_{2} \mathrm{SO}_{3}\right.$; CAS No. 7782-99-2) at $50^{\circ} \mathrm{C}$ for carbonate removal prior to high-temperature combustion of the dried residue. Gibbs reported OC losses ranging from 10 to $80 \%$ when using stronger mineral acids such as $\mathrm{HCl}, \mathrm{H}_{2} \mathrm{SO}_{4}$, and $\mathrm{HNO}_{3}$, compared with losses of less than $2 \%$ when using $\mathrm{H}_{2} \mathrm{SO}_{3}$ (although specific details of the acidifications were not stated).

In summary, a nonvolatile TOC quantitation method should: (1) dry samples and residues under mild conditions that minimize losses of semivolatile organics; (2) grind sample material fine enough to homogenize it and increase its reaction rate with acid; (3) quantitatively remove all carbonate minerals using an acid that has the minimum undesirable effects on the samples, instrument, and laboratory personnel; (4) accurately correct for carbon blanks due to grinding and acidification; (5) retain all organic carbon released from the sample material during acid treatment; (6) oxidize the residue under conditions that ensure complete conversion of organic carbon to $\mathrm{CO}_{2} ;(7)$ quantitate the evolved $\mathrm{CO}_{2}$ precisely and accurately; and (8) minimize total analysis time and labor. Once a test method has been designed to meet these criteria, its performance should be independently and systematically evaluated by analysts who might use it in their work.

According to an International Union of Pure and Applied Chemistry definition (Horwitz 1989), a collaborative analytical study is one in which a minimum of five laboratories determine the performance characteristics of a single, particular method of analysis using a series of identical test materials. The overall goal of a such a study is to evaluate intralaboratory and interlaboratory precision, as well as any systematic errors. With these objectives in mind, a proposed method for the analysis of low-TOC aquifer materials was tested independently in six laboratories. It was hoped that appreciably better accuracy and 
Table 1 Test material descriptions

\begin{tabular}{|c|c|c|c|c|c|}
\hline \multirow[b]{2}{*}{$\begin{array}{l}\text { Test } \\
\text { material }\end{array}$} & \multirow[b]{2}{*}{$\begin{array}{l}\text { Description } \\
\text { (depth interval) }\end{array}$} & \multirow[b]{2}{*}{$\begin{array}{l}\text { Major minerals, } \\
\text { XRD percentages }\end{array}$} & \multicolumn{3}{|c|}{ Approximate values } \\
\hline & & & $\begin{array}{l}\mathrm{TC} \\
\left(\mathrm{mg} \mathrm{g}^{-1}\right)\end{array}$ & $\begin{array}{l}\text { TOC } \\
\left(\mathrm{mg} \mathrm{g}^{-1}\right)\end{array}$ & $\begin{array}{l}\text { TIC } \\
\left(\mathrm{mg} \mathrm{g}^{-1}\right)\end{array}$ \\
\hline 1 & NIST SRM 88b & Dolomite, $99.5 ;$ quartz, 0.5 & 126.5 & 0.5 & 125.9 \\
\hline 2 & $\begin{array}{l}\text { Aquifer material core } A \\
\quad(76-98 \mathrm{~cm})\end{array}$ & $\begin{array}{l}\text { Quartz, 63.1; dolomite, 18.0; } \\
\text { feldspars, 13.6; calcite, 5.2 }\end{array}$ & 28.8 & 1.7 & 27.2 \\
\hline 3 & $\begin{array}{l}\text { Aquifer material core A } \\
\quad(262-284 \mathrm{~cm})\end{array}$ & $\begin{array}{r}\text { Quartz, 87.0; feldspars, } 5.9 ; \\
\text { dolomite, 5.5; calcite, } 1.6\end{array}$ & 12.8 & 2.1 & 10.0 \\
\hline 4 & $\begin{array}{l}\text { Aquifer material core SC } \\
(317-415 \mathrm{~cm})\end{array}$ & $\begin{array}{l}\text { Quartz, 54.5; dolomite, } 28.9 ; \\
\text { calcite, 9.4; feldspars, } 7.2\end{array}$ & 48.2 & 0.6 & 46.9 \\
\hline 5 & $\begin{array}{l}\text { Aquifer material core } 40 \\
\quad(60-125 \mathrm{~cm})\end{array}$ & $\begin{array}{r}\text { Quartz, 91.6; feldspars, 5.2; } \\
\text { dolomite, } 2.6 ; \text { calcite, } 0.5\end{array}$ & 19.6 & 13.5 & 4.6 \\
\hline
\end{tabular}

precision could be achieved than had been achieved in a previous interlaboratory comparison study of six different TOC methods (Powell and others 1989).

\section{Materials and instrumentation}

Ideally an interlaboratory method evaluation should use test materials for which analytical values have been certified by a recognized authority, such as the National Institute for Standards and Technology (NIST). Unfortunately, no available standard reference material (SRM) is similar in composition to sandy aquifer materials that contain moderate levels of carbonate together with low levels of organic carbon. (NIST reports total SRM carbon as weight percent $\mathrm{CO}_{2}$, but does not report TIC or TOC values.) Four authentic aquifer materials and one highTIC, low-TOC SRM were selected as challenging test materials for this blind collaborative method evaluation. Although there are no certified TOC values, it was anticipated that the mean of all reported results for each test material could be used as a consensus value.

Test material (TM) 1 is dolomitic limestone, SRM 88b (certificate date October 1987). It was used as received from NIST without further grinding (nominal size $<0.25 \mathrm{~mm}$ ). TM 2-TM 5 are authentic aquifer materials collected at Sleeping Bear Dunes near Empire, Michigan, USA. After drying at $40^{\circ} \mathrm{C}$, the aquifer materials were ground to $<0.149 \mathrm{~mm}$ using a Bel-Art Micro-Mill with a stainless steel blade. (Ideally, a corundum shatterbox or similar carbon-free grinder should be used; however, none was available at the laboratory that prepared the test materials.) The ground aquifer materials were split manually by carefully coning and quartering (Allman and Lawrence 1972) on clean aluminum foil using a clean stainless steel spatula. Subsamples $(\sim 20 \mathrm{~g})$ of each of the five test materials, identified only by number, were distributed to the participating laboratories. The test materials were analyzed by the participants without further grinding. Table 1 lists the results of semiquantitative $\mathrm{x}$-ray diffraction (XRD) analysis. Dolomite and calcite are the only discernible carbonate minerals. Siderite was not present in any of the test samples at levels detectable by XRD.

The instrumentation used by each laboratory is listed in Table 2 . The UIC carbon analyzer combusts $0.02-0.20 \mathrm{~g}$ of sample in a rectangular sample boat at $950^{\circ} \mathrm{C}$ in a stream of high-purity, $\mathrm{CO}_{2}$-free oxygen inside a resistanceheated, quartz-tube furnace. Combustion water and oxides of nitrogen and of sulfur are trapped out of the product gas stream before the $\mathrm{CO}_{2}$ is titrated coulometrically. Halogen species in the product gas stream are normally removed by silver wool inside the heated zone. However, $\mathrm{HCl}$-acidified sample residues contain such high concentrations of $\mathrm{CaCl}_{2}$ that incompletely trapped chlorine species interfere with coulometric titration. The LECO carbon analyzer combusts $0.15-0.5 \mathrm{~g}$ of dry sample in a ceramic crucible at temperatures up to $1370^{\circ} \mathrm{C}$. The $\mathrm{CO}_{2}$ evolved from the sample passes through halogen and water traps before being quantitated by a calibrated,
Table 2 Method details for seven participating laboratories

\begin{tabular}{|c|c|c|c|c|}
\hline $\begin{array}{l}\text { Lab } \\
\text { ID }\end{array}$ & $\begin{array}{l}\text { Replicate } \\
\text { weight (mg) }\end{array}$ & $\begin{array}{l}\text { Total acid } \\
\text { used (ml) }\end{array}$ & $\begin{array}{l}\text { TOC } \\
\text { instrument }\end{array}$ & Comments \\
\hline A & $30-90$ & 9 & UIC 5000 & $\begin{array}{l}\text { Samples were acidified before transfer to } \\
\text { combustion boats }\end{array}$ \\
\hline B & $20-30$ & 12 & LECO WR-112 & Porous combustion crucibles leaked acid \\
\hline $\mathrm{C}$ & $20-50$ & $3-18$ & UIC 5000 & \\
\hline $\mathrm{D}$ & $20-30$ & $3-18$ & UIC CM 120 & Salt crust hindered sample acidification \\
\hline E & $400-800$ & $5-9$ & $\begin{array}{l}\text { LECO CS-225; } \\
\text { Dohrmann DC180 }\end{array}$ & $\begin{array}{l}\text { Used } 2 \mathrm{M} \mathrm{HNO}_{3} \text { for acidification; } \\
\text { determined TOC as ASOC + AIOC }\end{array}$ \\
\hline $\mathrm{F}$ & $250-500$ & $9-12$ & LECO CS-444 & Did not determine TIC \\
\hline $\mathrm{G}$ & $80-130$ & 9 & UIC 5000 & \\
\hline
\end{tabular}


infrared-absorbance detector. For uniformity in this collaborative study, a combustion temperature of $950^{\circ} \mathrm{C}$ (the approximate working limit for quartz furnace tubes) was used with both types of instrument.

Also for the sake of uniformity, $\mathrm{H}_{2} \mathrm{SO}_{3}$ was specified for carbonate removal in the test method. $\mathrm{H}_{2} \mathrm{SO}_{3}$ does not react with labile organic compounds. Its vapors are much less corrosive to metal objects in the laboratory than are those of $\mathrm{HCl}, \mathrm{HNO}_{3}$, or $\mathrm{HClO}_{4}$. Combustion of residues containing its salts do not interfere with either the LECO or the UIC instruments. However, the use of $\mathrm{H}_{2} \mathrm{SO}_{3}$ acid for carbonate removal does entail two problems. The first problem is that the concentration of commercially available $\mathrm{H}_{2} \mathrm{SO}_{3}$ is only $0.73 \mathrm{M}$. At this concentration, $1 \mathrm{ml}$ of acid can remove no more than $0.36 \mathrm{mg}$ of calcite. To prepare a $10-\mathrm{mg}$ sample of a material that is $90 \%$ calcite for TOC analysis, one must add a minimum of $25 \mathrm{ml}$ of acid. In order to minimize OC losses due to transfers, it is advantageous to acidify the subsample in the same vessel in which it will be combusted. If a combustion boat with a 5-ml capacity is used, then five or more additions and evaporations of acid over a period of several days are required. Carbonate removal with dilute acid in a smallvolume vessel is time consuming. The second problem is that even the best reagent-grade $\mathrm{H}_{2} \mathrm{SO}_{3}$ available may contain appreciable noncarbonate carbon contamination. Chemical companies do not assay their $\mathrm{H}_{2} \mathrm{SO}_{3}$ or other mineral acids for carbon. Because $\mathrm{H}_{2} \mathrm{SO}_{3}$ is a reducing agent, it is not possible to remove organic carbon by adding hydrogen peroxide and heating, as is done to purify $\mathrm{H}_{3} \mathrm{PO}_{4}$. This means that the carbon contribution from the acid added must be accurately corrected for in all acidified samples. Unfortunately, the first lot of sulfurous acid that was sent to all laboratories could not be used because the carbon blank $\left(\sim 1.3 \mathrm{mg} \mathrm{C} \mathrm{m1}^{-1}\right)$ was higher than the expected sample TOC levels, making reagent blank correction unreliable. Replacement bottles of $\mathrm{H}_{2} \mathrm{SO}_{3}$ (Baker reagent grade, blank $<8 \mu \mathrm{g} \mathrm{C} \mathrm{ml}^{-1}$ ) were shipped to all the laboratories, except for Lab $\mathrm{E}$, which had already proceeded using $2 \mathrm{M} \mathrm{HNO}_{3}$ instead.

\section{Test method for determination of nonvolatile TOC in aquifer materials}

The following method was used by six of the participating laboratories to analyze the five test materials. (The original method text has been revised here to improve clarity.)

1. Analyze a minimum of two reference standards for carbon that span the range of expected experimental concentrations. Keep appropriate quality control charts and verify instrument performance daily before proceeding to analyze the actual samples and acid blanks. Protect all samples, standards, reagent, and equipment from dust and other potential sources of contamination.

2. Determine TC for each test material by combustion of nonacidified subsamples at $950^{\circ} \mathrm{C}$. If possible, also determine TIC using a proven, selective instrumental meth- od (such as coulometric titration of the $\mathrm{CO}_{2}$ released by acidification). Estimate the approximate TOC value for each test material by subtracting TIC from TC.

3. Choose the weight of each test material to be acidified for replicate TOC determinations. This weight is a compromise among the instrument detection limit, the combustion vessel volume, and the number and volume of acid additions required to remove all carbonate. Use the smallest replicate weight necessary to contain sufficient organic carbon for the desired level of precision with the instrument being used $(\sim 0.1-0.5 \mathrm{~g}$ sample with LECO, and $\sim 0.02-0.05 \mathrm{~g}$ with UIC). Based on the estimated sample carbonate content and the combustion vessel's liquid capacity, determine how many successive acid additions must be performed. Assume that $1 \mathrm{ml}$ of $0.73 \mathrm{M} \mathrm{H}_{2} \mathrm{SO}_{3}$ can remove no more than $0.36 \mathrm{mg}$ of $\mathrm{CaCO}_{3}$ and allow for at least a $10 \%$ excess of acid. If too many repeated acidifications would be required, choose a proportionately smaller replicate weight.

4. Weigh out a minimum of five replicates of each test material into muffled, tared combustion vessels that have been inscribed with unique, permanent identification numbers. Acidify and dry replicates in the same vessels that will be used for residue combustion, thereby avoiding TOC losses that result from sample transfers. When analyzing low-organic, high-inorganic samples, use the largest boats or crucibles available for the particular instrument. To quantitatively retain all "acid-soluble" organic carbon (ASOC), the vessels must be nonporous so that acid does not penetrate, even after standing for several days. With LECO instruments, use crucible liner \# 529-036 with crucible \# 528-018 (or equivalents). With UIC instruments, use the largest available glazed porcelain boat that will fit inside the quartz furnace; the 25-mm-ID tube (CM211013) and breech block (CM101-127) are recommended in place of the smaller-capacity $15-\mathrm{mm}$ versions.

5. Dry the subsamples in the combustion vessels at $40^{\circ} \mathrm{C}$ until weights are constant to within $\pm 0.2 \mathrm{mg}$ (approximately $24 \mathrm{~h}$ ). Record all sample weights to $\pm 0.1 \mathrm{mg}$ or better. For ease in organizing, transporting, drying, and acidifying subsamples, group the replicate sets in muffled, $150 \times 20$-mm glass petri dishes. To allow adequate venting when drying subsamples while protecting them from dust, the petri dish cover should be supported 5-10 $\mathrm{mm}$ above the lip of the dish bottom. Suitable supports can be made by flame-bending short pieces of glass rod $(\sim 4 \times 25 \mathrm{~mm})$ into U-shaped spacers. Three of these glass Us are then hung inverted $120^{\circ}$ apart on the lip of the lower dish before the cover is set in place.

6. Cool samples to room temperature. Cautiously add the exact volume of $0.73 \mathrm{M} \mathrm{H}_{2} \mathrm{SO}_{3}$ to each replicate (as selected in step 3). Pay close attention to avoid foam-over and loss of sample or acid. Add precisely the same volume of acid $( \pm 0.05 \mathrm{ml})$ to three empty combustion vessels, so that the residual organic carbon blank value for the acid can be determined. Allow the acid to evaporate from the samples and blanks overnight at $40^{\circ} \mathrm{C}$. Incubation temperatures higher than $40^{\circ} \mathrm{C}$ can cause measurable losses of semivolatile organics, while lower temperatures require 
excessively long reaction times. An acid-resistant, thermostatted drying oven simplifies sample acidification and drying and gives the best temperature control. If such a drying oven is not available, then subsamples arranged in covered, vented petri dishes in a fume hood can be warmed to approximately $40^{\circ} \mathrm{C}$ by a $250-\mathrm{W}$ reflectorized infrared heat lamp suspended approximately $35 \mathrm{~cm}$ above them. Alternatively, a thermostatted hotplate can be used to warm one or two petri dishes. (Variations in ambient air temperature and the rate of airflow though the fume hood can significantly affect the incubation temperature.) Repeat the acidification and evaporation steps at least until the calculated volume of acid has been added and given time to react.

7. After acidification is complete, as indicated by complete absence of effervescence, allow the residual liquid to evaporate at $40^{\circ} \mathrm{C}$. The replicate residues do not need to be dried to constant weight at this stage, because the reference weight from which percent TOC is calculated was determined prior to acid treatment. However, residual acid shortens the life of instrument components and may interfere with $\mathrm{CO}_{2}$ detection, so sample replicates should be reasonably dry before they are combusted.

8. Combust the acid-treated replicates at $950^{\circ} \mathrm{C}$. Specific sample combustion conditions depend upon the particular instrument being used. Repeatedly check the condition of instrument components. Gas leaks and exhausted reagents are two of the most common sources of instrumental error.

Although they are not strictly part of the collaborative study because the same test method was not followed, the results reported by Lab $\mathrm{E}$ are included for comparison with those from the six laboratories that followed the test method. Lab $\mathrm{E}$ deviated from the specified test method in three major respects. First, $2 \mathrm{M} \mathrm{HNO}_{3}$ was used in place of $0.73 \mathrm{M} \mathrm{H}_{2} \mathrm{SO}_{3}$ for carbonate removal. Second, replicates were acidified in glass centrifuge tubes rather than in combustion vessels, requiring additional sample transfer steps. Third, the acidic supernatant containing the ASOC was analyzed separately using a Dohrmann DC180 carbon analyzer that has liquid sample capabilities. The acidinsoluble organic carbon (AIOC) value was determined by combustion of the centrifuged residue solids in a LECO carbon analyzer. Lab E computed TOC as AIOC plus ASOC.

\section{Results and discussion}

Table 3 summarizes the analytical results reported by each of the seven laboratories (including Lab E, although they
Table 3 Summary of interlaboratory study results

\begin{tabular}{|c|c|c|c|c|c|c|}
\hline Row & $\begin{array}{l}\text { Parameter } \\
\text { (units) }\end{array}$ & TM 1 & TM 2 & TM 3 & TM 4 & TM 5 \\
\hline 1 & 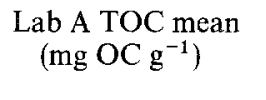 & $\begin{array}{c}99.26^{*} \\
(0.78) \\
{\left[0.8^{\circ}\right]}\end{array}$ & $\begin{array}{l}13.68^{*} \\
(0.28) \\
{[2.0 \%}\end{array}$ & $\begin{array}{c}3.00 \\
(0.32) \\
{[10.5 \%]}\end{array}$ & $\begin{array}{l}26.62^{*} \\
(1.11) \\
{[4.2 \%}\end{array}$ & $\begin{array}{c}13.80 \\
(1.01) \\
{[7.3 \%]}\end{array}$ \\
\hline 2 & $\begin{array}{l}\text { Lab B TOC mean } \\
\quad\left(\mathrm{mg} \mathrm{OC}^{-1}\right)\end{array}$ & $\begin{array}{c}57.56^{*} \\
(20.36) \\
{[35.4 \%]}\end{array}$ & $\begin{array}{c}13.45^{*} \\
(5.03) \\
{[37.4 \%]}\end{array}$ & $\begin{array}{c}6.72^{*} \\
(2.91) \\
{[43.4 \%]}\end{array}$ & $\begin{array}{l}38.28^{*} \\
(0.62) \\
{\left[1.6^{\circ} \%\right.}\end{array}$ & $\begin{array}{l}17.28 \\
(0.35) \\
{\left[2.0^{\circ}\right.}\end{array}$ \\
\hline 3 & $\begin{array}{l}\text { Lab C TOC mean } \\
\left(\mathrm{mg} \mathrm{OC}^{-1}\right)\end{array}$ & $\begin{array}{c}0.44 \\
(0.33) \\
{[6.8 \%]}\end{array}$ & $\begin{array}{c}1.46 \\
(0.02) \\
{[1.3 \%]}\end{array}$ & $\begin{array}{c}1.97 \\
(0.09) \\
{[4.5 \%]}\end{array}$ & $\begin{array}{c}0.54 \\
(0.03) \\
{[5.6 \%]}\end{array}$ & $\begin{array}{c}13.32 \\
(0.39) \\
{[2.9 \%]}\end{array}$ \\
\hline 4 & $\begin{array}{l}\text { Lab D TOC mean } \\
\quad\left(\mathrm{mg} \mathrm{OC} \mathrm{g}^{-1}\right)\end{array}$ & $\begin{array}{c}63.56^{*} \\
(4.85) \\
{\left[7.6^{\circ} \%\right]}\end{array}$ & $\begin{array}{c}1.55 \\
(0.15) \\
{[9.4 \%]}\end{array}$ & $\begin{array}{c}1.91 \\
(0.06) \\
{[3.0 \%]}\end{array}$ & $\begin{array}{c}6.17^{*} \\
(1.65) \\
{[26.8 \%]}\end{array}$ & $\begin{array}{l}14.48 \\
(0.41) \\
{[2.8 \%]}\end{array}$ \\
\hline 5 & $\begin{array}{l}\text { Lab E TOC mean } \\
\quad\left(\mathrm{mg} \mathrm{OC}^{-1}\right)\end{array}$ & $\begin{array}{c}0.54 \\
(0.04) \\
{[7.7 \%]}\end{array}$ & $\begin{array}{c}1.53 \\
(0.10) \\
{[6.4 \%]}\end{array}$ & $\begin{array}{c}1.60 \\
(0.20) \\
{[12.5 \%]}\end{array}$ & $\begin{array}{c}0.60 \\
(0.03) \\
{[5.4 \%]}\end{array}$ & $\begin{array}{c}9.83 \\
(0.24) \\
{[2.5 \%]}\end{array}$ \\
\hline 6 & $\begin{array}{l}\text { Lab F TOC mean } \\
\quad\left(\mathrm{mg} \mathrm{OC}^{-1}\right)\end{array}$ & $\begin{array}{c}74.08^{*} \\
(0.88) \\
{[1.2 \%]}\end{array}$ & $\begin{array}{c}2.22 \\
(0.14) \\
{[6.2 \%]}\end{array}$ & $\begin{array}{c}1.90^{*} \\
(0.09) \\
{[4.7 \%]}\end{array}$ & $\begin{array}{c}6.20^{*} \\
(1.87) \\
{[22.8 \%]}\end{array}$ & $\begin{array}{l}12.94 \\
(0.30) \\
{[2.3 \%]}\end{array}$ \\
\hline 7 & $\begin{array}{l}\text { Lab G TOC mean } \\
\quad\left(\mathrm{mg} \mathrm{OC}^{-1}\right)\end{array}$ & $\begin{array}{c}61.52^{*} \\
(5.05) \\
{[8.2 \%]}\end{array}$ & $\begin{array}{c}1.62 \\
(0.11) \\
{[6.5 \%]}\end{array}$ & $\begin{array}{c}2.16 \\
(0.16) \\
{[7.4 \%]}\end{array}$ & $\begin{array}{c}4.67^{*} \\
(2.31) \\
{[49.6 \%]}\end{array}$ & $\begin{array}{c}13.00 \\
(0.76) \\
{\left[5.9^{\circ} \%\right]}\end{array}$ \\
\hline 8 & $\begin{array}{l}\text { Pooled TOC mean } \\
\quad\left(\mathrm{mg} \mathrm{OC}^{-1}\right)\end{array}$ & $\begin{array}{l}50.99^{*} \\
(35.85) \\
{[70 \%]}\end{array}$ & $\begin{array}{c}5.07^{*} \\
(5.79) \\
{\left[114^{\circ} \%\right.}\end{array}$ & $\begin{array}{c}2.75 \\
(2.04) \\
{\left[74^{\circ}\right]}\end{array}$ & $\begin{array}{c}11.87^{*} \\
(13.84) \\
{\left[117^{\circ}\right.}\end{array}$ & $\begin{array}{l}13.52 \\
(2.16) \\
{[16 \%]}\end{array}$ \\
\hline 9 & $\begin{array}{l}\text { Pooled TC mean } \\
\quad\left(\mathrm{mg} \mathrm{C}^{-1}\right)\end{array}$ & $\begin{array}{c}126.70 \\
(1.84) \\
{[1.5 \%]}\end{array}$ & $\begin{array}{c}28.84 \\
(1.43) \\
{[4.9 \%]}\end{array}$ & $\begin{array}{c}12.83 \\
(0.78) \\
{[6.1 \%]}\end{array}$ & $\begin{array}{c}48.54 \\
(2.17) \\
{[4.4 \%]}\end{array}$ & $\begin{array}{c}19.63 \\
(0.96) \\
{[4.9 \%]}\end{array}$ \\
\hline 10 & $\begin{array}{l}\text { Pooled TIC mean } \\
\quad\left(\mathrm{mg} \mathrm{IC} \mathrm{g}^{-1}\right)\end{array}$ & $\begin{array}{c}125.67 \\
(0.37) \\
{[0.3 \%]}\end{array}$ & $\begin{array}{c}27.18 \\
(0.74) \\
{[2.7 \%]}\end{array}$ & $\begin{array}{c}9.97 \\
(0.45) \\
{[4.5 \%]}\end{array}$ & $\begin{array}{c}46.91 \\
(1.00) \\
{[2.1 \%]}\end{array}$ & $\begin{array}{c}4.55 \\
(0.92) \\
{[20.3 \%]}\end{array}$ \\
\hline 11 & $\begin{array}{l}\text { TOC }_{\text {EST }} \\
\quad\left(\mathrm{mg} \mathrm{OC}^{-1}\right)\end{array}$ & 1.03 & 1.66 & 2.86 & 1.63 & 15.08 \\
\hline 12 & $\mathrm{TIC}^{\mathrm{T}} \mathrm{TCC}_{\mathrm{EST}}$ & 122 & 16 & 3.5 & 29 & 0.30 \\
\hline
\end{tabular}

${ }^{a}$ Asterisks indicate biased values. Values in parentheses are standard deviations; values in brackets are relative standard deviations 
used a different method). Rows 1-7 contain the mean TOC values for five replicates of each of the five test materials. Standard deviations (SD) are given in parentheses, and relative standard deviations (RSD) are enclosed in square brackets. Row 8 contains the pooled (that is, all replicate values from all seven laboratories taken together) TOC mean, SD, and RSD for each test material. Row 9 gives corresponding values for pooled $\mathrm{TC}$, and row 10 gives pooled TIC. Interlaboratory agreement of the reported results for $\mathrm{TC}(\mathrm{RSD}=1.5-6.1 \%)$ and for TIC (RSD $=0.3-20.3 \%$ ) was much better than for TOC $\left(\mathrm{RSD}=16-117 \%\right.$ ). The $\mathrm{TOC}_{\mathrm{EST}}$ (working estimate of TOC) values in row 11 are calculated by subtracting pooled TIC from respective pooled TC values. Row 12 contains quotients for pooled TIC divided by $\mathrm{TOC}_{\mathrm{EST}}$, which indicate comparative sample difficulty.

Initially, it was planned that mean reported TOC values could be used as the target values with which to evaluate laboratory accuracy. However, because the errors in the data sets are predominantly systematic rather than random, the pooled means are biased. Statistical outlier exclusion methods that assume a normal distribution of reported values centered about the correct value cannot be used. An alternative method of excluding strongly biased values is employed. Interlaboratory agreement of TC values as well as TIC values is reasonably good, as indicated by the pooled RSD values. A working estimate of TOC for each test material $\left(\mathrm{TOC}_{\mathrm{EST}}\right.$ in row 11 of Table 3 ) is computed by subtracting the pooled TIC mean (row 10) from the respective pooled TC mean (row 9). If a laboratory TOC mean (rows $1-7$ ) is more than twice the respective $\mathrm{TOC}_{\mathrm{EST}}$, then that mean is judged to be strongly positively biased due to incomplete carbonate removal. The asterisks in Table 3 indicate values for which the estimated error is more than $100 \%$.

One possible measure of overall performance by all seven laboratories is pooled TOC error. For each of the test materials, the pooled TOC error is calculated as the pooled TOC mean (row 8 in Table 3 ) minus TOC $_{\text {EST }}$ (row 11). Figure 1 plots the pooled TOC error as a function of pooled TIC/TOC for each of the test materials. The regression of the five points is unexpectedly linear $\left(R^{2}=\right.$ 0.998). The reasons for this close correlation are unknown. This graph demonstrates dramatically that samples high in TIC and low in TOC present the greatest analytical difficulties, even when special care is taken during an interlaboratory study.

Figure 2 summarizes the TC, TIC, and TOC results reported by each laboratory for each of the five test materials as box plots. The precision of each set of replicate values is plotted as a box with an attached error bar. The upper and lower ends of each box mark the 75th and 25th statistical percentiles, while the line across the width of the box indicates the 50th percentile (median). The ends of the error bars that extend above and below the box mark the 90 th and 10th percentiles. Shorter boxes with shorter error bars represent better analytical precision. Data sets with comparatively high precision plot as horizontal lines with no visible vertical extent, while more variable results plot

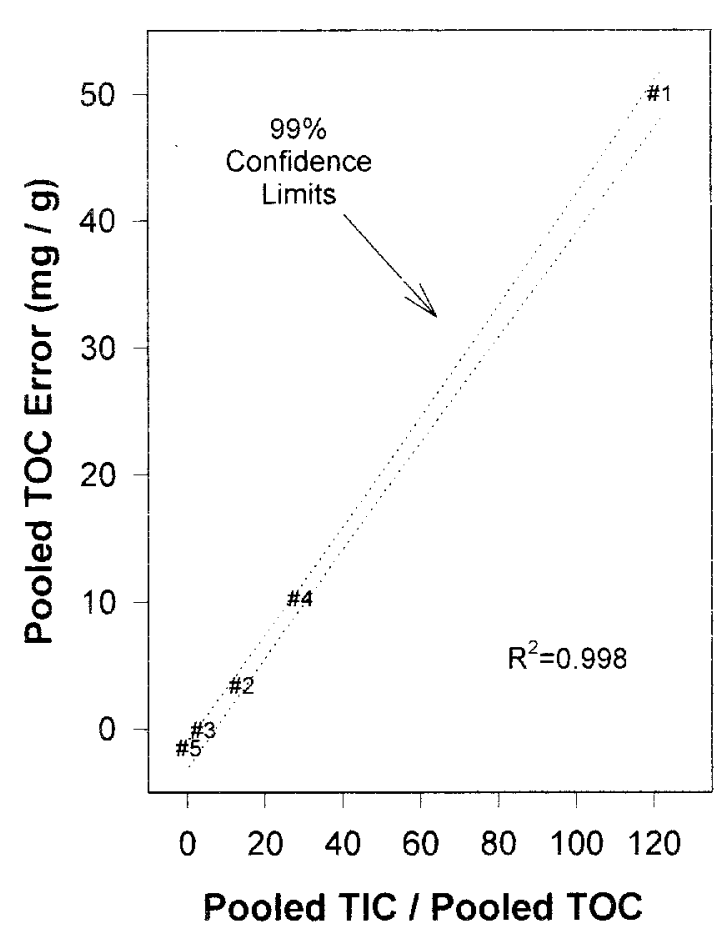

Fig. 1 Estimated mean TOC error plotted as a function of mean TIC/TOC for five test materials

as taller boxes with discrete error bars. The graphs of $\mathrm{TC}$, TIC, and TOC data for each test material share the same vertical scale, but the scales differ from one test material to another to aid legibility. The test material number is located at the right side of each row of three graphs. Plots are missing in the second column of graphs for Labs A, E, and $\mathrm{F}$ because they did not analyze the test materials for TIC.

Figure 2 illustrates some trends and discrepancies among the reported values. Interlaboratory agreement is reasonably good both for TC and for TIC in all five test materials, but the TOC results are much more scattered. By definition, for each test material TOC should equal TC minus TIC. If TIC is nearly equal to TC, then TOC should be very small. However, the graphs show that this is not always the case. For example, the TOC values reported by Labs A, B, D, F, and G for TM 1 are much larger than the difference between TC and TIC. A pattern of similar but lesser errors is evident in the graphs for TM 4. Overall, there is a positive bias in many of the reported TOC values resulting from incomplete carbonate removal prior to residue combustion.

It is possible that the TOC results for TM 1 (SRM 88b) would have been better if it had been ground finer than the nominal $<0.25-\mathrm{mm}$ size provided by NIST. A smaller particle size would have facilitated complete carbonate removal by acidification. Unfortunately, the grinder used to prepare the other test materials for this study was known to contribute "noncarbonate carbon" contamination from the steel components. High-temperature combustion of acidified residue does not distinguish true organic carbon from elemental or carbide carbon. In the 
Fig. 2 Statistical box plots of $\mathrm{TC}, \mathrm{TIC}$, and TOC results from the interlaboratory method evaluation

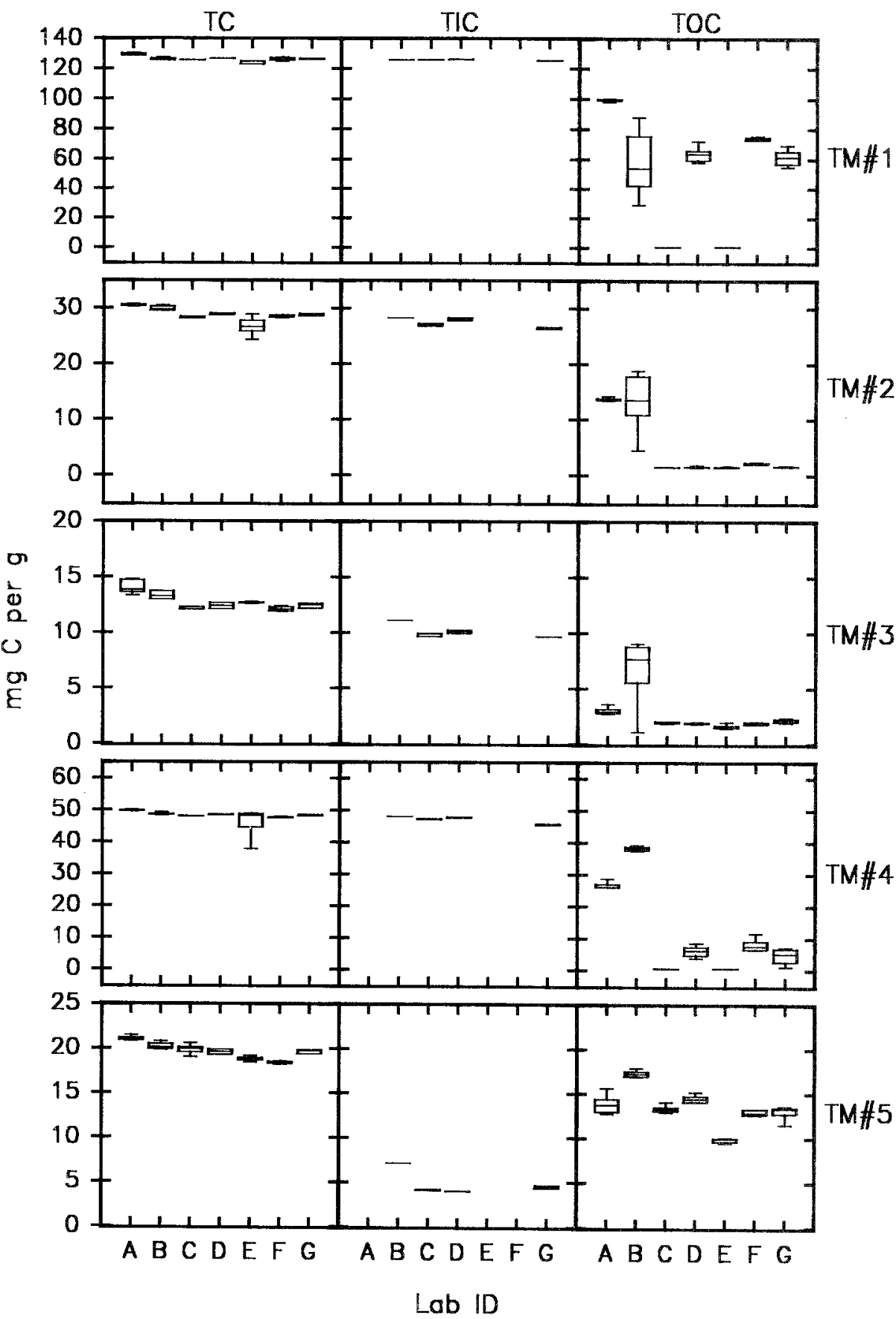

worst case observed, when a test sample of muffled quartz sand $(\sim 20 \mathrm{~g})$ was ground from an initial size of $<2.0 \mathrm{~mm}$ down to $<0.149 \mathrm{~mm}$, TC increased by $0.092 \mathrm{mg} \mathrm{g}^{-1}$ of sample. An increment of $0.092 \mathrm{mg} \mathrm{g}^{-1}$ sample is small compared with the NIST value of $126.467 \mathrm{mg} \mathrm{TC} \mathrm{g}^{-1}$. However, since the estimated TOC value for TM 1 is only $0.49 \mathrm{mg} \mathrm{C} \mathrm{g}^{-1}$, an increase of $0.092 \mathrm{mg} \mathrm{C} \mathrm{g}^{-1}$ would increase noncarbonate carbon by approximately $19 \%$. In order to maintain the original composition, and to keep TOC as low as possible in the most challenging test material, it was decided to use SRM $88 \mathrm{~b}$ as received without further grinding. For the purposes of this interlaboratory comparison, contamination of TM 2-TM 5 with grinder- derived carbon was not a problem, because the composition of the split samples was the same for all laboratories.

Ideally, before a collaborative study of this type proceeds with the actual analysis of test materials, all the participants should be thoroughly familiar with the method being evaluated. However, in most laboratories the demands of other projects make it difficult to set aside time to experiment with a new method. Differing levels of experience may account in large part for the degrees of success achieved using the laborious acidification and drying techniques. Of the six laboratories that followed the specified test method, only Lab $\mathrm{C}$ had extensive experience using it prior to this interlaboratory study, and only Lab C consis- 
tently removed the carbonate from all five test materials before TOC combustion. Similarly, Lab E successfully removed the carbonate using their own established method and achieved good precision and TOC values similar to those reported by Lab C. Unfortunately, to some extent, analysts in the other five laboratories were still learning the test method when they analyzed the test materials. A delay of more than six weeks replacing the contaminated $\mathrm{H}_{2} \mathrm{SO}_{3}$ with a new lot did not allow adequate time to practice the test method. Furthermore, the laboratories that did not determine TIC directly were at a particular disadvantage, because they could only guess how much material to use for each replicate and how much acid would be required for carbonate removal.

This collaborative study focused on the problems of effective carbonate removal from aquifer materials by acidification prior to nonvolatile TOC quantitation by high temperature combustion and $\mathrm{CO}_{2}$ quantitation. $\mathrm{Ob}$ viously many other important practical and theoretical questions concerning sample definition, collection, preservation, and composition could not be considered within the scope of this work.

\section{Further recommendations}

The following additional recommendations are based upon the results of this collaborative study, as well as upon the work that preceded it (Caughey, Barcelona, and Powell, unpublished data). To optimize homogeneity and reactivity, grind samples of aquifer material smaller than $0.063 \mathrm{~mm}$. In terms of the speed of particle size reduction, a shatterbox is preferable to either a rotary blade mill or a motorized mortar and pestle. Before using any grinder for actual samples, determine the carbon blank for the grinding process using precombusted silica sand. Steel, carbide, and polymeric grinder components exposed to the sample can contribute measurable levels of carbon. Corundum grinding surfaces are recommended for pulverizing lowcarbon aquifer materials. Designs that permit cooling the grinder head $\left(<15^{\circ} \mathrm{C}\right)$ can improve the retention of semivolatile organic species. Pulverizing materials while they are slightly moist can minimize both the grinding time and the loss of sample as dust. However, water will exacerbate carbon contamination from corroding steel parts.

To minimize losses and contamination while sieving, use only a small subsample of the ground material for particle size range determination. Do not sieve the bulk of the ground sample that will actually be used for the carbon analyses.

Determine the TOC method blank for each bottle of $\mathrm{H}_{2} \mathrm{SO}_{3}$ or other mineral acid before using it with actual samples. Periodic retesting of the acid blank is important, because carbon levels may increase by a factor of ten or more after a bottle has been opened and then stored for a few weeks. A suspected source of this carbon contamination is the plastic caps on acid bottles. Storage of acids in glass reagent bottles fitted with tapered ground-glass stop- pers should lessen this problem. It is possible that purer, more concentrated sulfurous acid can be produced in the laboratory by dissolving sulfur dioxide gas (commercially available in cylinders as $>99.9 \%$ ) in high-purity water. We have not yet tested $\mathrm{H}_{2} \mathrm{SO}_{3}$ produced in this manner for carbonate removal.

The results obtained by Lab E using an ASOC-plusAIOC approach warrant follow-up testing. The magnitude and frequency of TOC errors due to losses during residue transfers and the total sample processing time required should be evaluated. Dilute aqueous $\mathrm{H}_{3} \mathrm{PO}_{4}(2 \mathrm{M})$ should be tested as a nonoxidizing alternative to $\mathrm{HNO}_{3}$ for carbonate digestion. If the acidic liquid phase is removed from the sample residue by centrifugation or filtration, then the UIC furnace components may better tolerate the lesser amounts of phosphates retained in the solid fraction. No serious problems resulting from the combustion of residual phosphates have been reported by those using LECO systems.

\section{Conclusions}

This study demonstrated that accurate quantitation of nonvolatile TOC at low levels in the presence of high levels of TIC in aquifer material remains problematic, even when special care is exercised. Incomplete removal of carbonate minerals prior to residue combustion is the single greatest source of the systematic positive bias observed in many of the reported TOC values. Acidifying and drying replicates in small vessels is labor-intensive. It is very difficult to determine when acidification is complete. One laboratory with previous experience using the test method achieved good precision and reasonable TOC values with all five test materials. However, because the test method is time consuming, it is primarily suitable for use with a limited number of important samples. Routine analysis of larger numbers of samples requires a simpler means of quantitative carbonate removal. Although it requires additional instrumentation and sample transfers, the ASOCplus-AIOC approach should be evaluated further.

Acknowledgments This work was supported by the Illinois DENR under Hazardous Waste Research and Information Center contract 90-076, and by USEPA RSKERL under cooperative agreement CR 817287-01. Mention of trade names does not indicate endorsement by the organizations that sponsored or conducted this research. The authors appreciate the valuable contributions made by B. Cai, T. Chow, R. Henderson, R. Hoch, R. Hughes, K. Maas, J. Peden, J. Pedersen, L. Pennington, D. Shaw, K. Surratt, C. West, H. Wilper, and $\mathbf{J} . \mathrm{Wu}$. 


\section{References}

Al-Aasm IS, Taylor BE, and South B (1990) Stable isotope analyses of multiple carbonate samples using selective acid extraction. Chem Geol. (Isotope Geosci) 80:119-125

Allman M and Lawrence DF (1972) Geological laboratory techniques. New York: Arco. $335 \mathrm{pp}$

Ball WP, Buehler CH, Harmon TC, Mackay DM, and Roberts PV (1990) Characterization of a sandy aquifer material at the grain scale. J Contam Hydrol 5:253-295

Barcelona MJ and Holm TR (1991) Oxidation-reduction capacities of aquifer solids. Environ Sci Technol 25:1565-1572

Chichester FW and Chaison RF (1992) Analysis of carbon in calcareous soils using a two temperature dry combustion infrared instrumental procedure. Soil Sci 153:237-241

Froelich PN (1980) Analysis of organic carbon in marine sediments. Limnol Oceanogr 25:564-572

Gibbs RJ (1977) Effects of temperature and time and of the oxidation agent used in organic carbon and nitrogen analyses of sediments and dissolved organic material. J. Sediment Petrol 47:547-550

Gu B, Schmitt J, Chen Z, Liang L, and McCarthy JF (1994) Adsorption and desorption of natural organic matter on iron oxide: Mechanisms and models. Environ Sci Technol 8:138-146

Horwitz W (1989) Definitions involved in interlaboratory studies. J Assoc Off Anal Chem 72:145-147
Jackson LL and Roof SR (1992) Determination of the forms of carbon in geologic materials. Geostand Newsl 16:317-323

Jones GA and Kaiteris P (1983) A vacuum-gasometric technique for rapid and precise analysis of calcium carbonate in sediments and soils. J Sediment Petrol 53:655-660

Krom MD and Berner RA (1983) A rapid method for the determination of organic and carbonate carbon in geological samples. J Sediment Petrol 53:660-663

Lion LW, Stauffer TB, and MacIntyre WG (1990) Sorption of hydrophobic compounds on aquifer material: Analysis methods and the effect of organic carbon. J Contam Hydrol 5:215-234

McCarthy JF and Zachara JM (1989) Subsurface transport of contaminants. Environ Sci Technol 23:496-502

Mingelgrin U and Gerstl Z (1983) Reevaluation of partitioning as a mechanism of nonionic chemicals adsorption in soils. J Environ Qual 12:1-11

Powell RM, Bledsoe BE, Johnson RL, and Curtis GP (1989) Interlaboratory methods comparison for the total organic carbon analysis of aquifer materials. Environ Sci Technol 23:1246-1249

Schilt AA (1979) Perchloric acid and perchlorates. Columbus Ohio: G.F. Smith Chemical Co. 189 pp

Stauffer TB, MacIntyre WG, and Wickman DC (1989) Sorption of nonpolar organic chemicals on low-carbon-content aquifer materials. Environ Toxicol Chem 8:845-852

Videtich PE (1981) A method for analyzing dolomite for stable isotopic composition. Sediment Petrol 51:661-662 